\title{
Report of the Editor 2020
}

\author{
Markus Schmid ${ }^{1}$
}

Published online: 4 March 2021

(c) Swiss Society for Financial Market Research 2021

In 2020, Financial Market and Portfolio Management further increased its international reputation, publishing high-quality original research relevant to financial practitioners and academics.

The table below shows details on submissions and publications of FMPM. We are happy to report a further substantial increase in the number of submissions. In 2020, a total of 255 manuscripts were submitted to the editorial office. This number only covers first submissions, submissions of revised papers are not included.

Submission and publication statistics

\begin{tabular}{llcrr}
\hline Number of manuscripts & 2020 & 2019 & 2018 & 2017 \\
\hline Submitted & 255 & 195 & 127 & 126 \\
Rejected (all/2020 subm.) & $235 / 224$ & 162 & 103 & 93 \\
In revision/review (all/2020 subm.) & $34 / 25$ & 28 & 27 & 31 \\
Accepted (all/2020 subm.) & $26 / 6$ & 15 & 12 & 10 \\
Published & 16 & 15 & 16 & 16 \\
\hline
\end{tabular}

Of the 255 newly submitted papers, 224 were rejected within the year. In total, 235 papers were rejected in 2020, and 11 of these papers were submitted to the journal before 2020. Of the 224 manuscripts that were submitted in 2020 and rejected within the same year, 217 manuscripts were desk-rejected by the editor, while the remaining 7 articles were initially admitted to the review process. As of December 31, 2020, 34 manuscripts, 25 of which were initially submitted in 2020, were either in revision with the authors or in the review process with the referees. A decision on those manuscripts is still pending. Six of the 255 papers submitted in 2020 were accepted for publication, after having being revised once or twice. Another 20 papers were accepted that were initially submitted in previous years. A total of 16 articles were published in four issues in 2020. The published articles cover a broad range of finance-related topics, including asset pricing, investments and portfolio management, market microstructure, and cryptocurrencies. In addition to the 16

Markus Schmid

markus.schmid@unisg.ch

1 Swiss Institute of Banking and Finance, University of St. Gallen, St. Gallen, Switzerland 
articles, we published four book reviews in 2020, which are not included in the table above. FMPM follows a double-blind peer review process. In a first step, submitted papers are screened by the editor and either desk-rejected or admitted to the anonymous peer review process.

In 2020, a total of 62 referee reports were written with an average turnaround time from submission to the sending of the referee reports to the authors of approximately six weeks. I would like to take this opportunity to thank all 49 individual reviewers providing reports in 2020. Without their valuable work, it would be impossible to edit and publish our journal. Their judgment and expertise essentially contribute to Financial Market and Portfolio Management.

In previous years, the prizes for the two best papers published in FMPM were awarded at the annual conference of the Swiss Society for Financial Market Research (SGF). Due to the SARS-Cov-2 pandemic situation, the 2020 annual conference unfortunately had to be canceled. The two awards were announced in the second issue of Volume 34 (2020) of FMPM. Peter Schmidt, Urs von Arx, Andreas Schrimpf, Alexander Wagner, and Andreas Ziegler received the "FMPM Best Paper Award" for their article "Common Risk Factors in International Stock Market," published in the third issue of Volume 33. The "ZKB Best Paper Award", sponsored by Zurich Cantonal Bank (ZKB), was presented to Florian Methling and Rüdiger von Nitzsch for their article "Thematic Portfolio Optimization: Challenging the Core Satellite Approach," published in the second issue of Volume 33. Both awards carry a cash prize of CHF 4,000. I congratulate all winners to their exceptional contributions to Financial Market and Portfolio Management!

Finally, I would like to thank all our contributors for their articles submitted to FMPM. We are grateful to all authors who submit their work to FMPM and we continue to invite submissions of interesting, relevant, and timely articles in the field of finance.

January 2021

Markus Schmid

Publisher's Note Springer Nature remains neutral with regard to jurisdictional claims in published maps and institutional affiliations. 